\title{
Studies on Character Association and Path Coefficient Analysis for Anaerobic Germination Traits, Yield and its Contributing Characters in Rice (Oryza sativa L.)
}

\author{
E. Umarani ${ }^{1}$, V. Hemalatha ${ }^{1}$, L.V. Subbarao ${ }^{2}$, C.N. Neeraja ${ }^{2}$, \\ Suneetha Kota ${ }^{2}$ and S. Narender Reddy ${ }^{1}$ \\ ${ }^{1}$ College of Agriculture, PJTSAU, Rajendranagar, Hyderabad-500030, India \\ ${ }^{2}$ Crop Improvement Section, ICAR-Indian Institute of Rice Research, Rajendranagar, \\ Hyderabad-500030, India \\ *Corresponding author
}

\begin{abstract}
A B S T R A C T
Keywords

Rice, correlations, Direct and indirect effects, Anaerobic germination, Yield

Article Info

Accepted:

04 March 2019

Available Online:

10 April 2019

In the present investigation cause of association and direct and indirect effects were estimated between anaerobic germination traits, yield and its contributing traits in twenty five hybrids, along with their ten parents and three checks of rice (Oryza sativa L.). Single plant yield registered positive significant association with number of tillers per hill, number of productive tillers per hill, panicle length, spikelet fertility, number of grains per panicle and 1000-grain weight indicating that these characters were important for yield improvement. Path coefficient analysis revealed that number of number of grains per panicle exserted the highest positive direct effect on grain yield followed by plant height, panicle length, spikelet fertility, anaerobic germination percentage, number of productive tillers per hill, seedling length and number of tillers per hill indicating that the selection for these characters was likely to bring about an overall improvement in single plant yield directly.
\end{abstract}

\section{Introduction}

Rice is the only crop in the world that is grown in most fragile ecosystem and hence second green revolution is possible only if rice research is undertaken vigorously and persistently to address specific abiotic and biotic stress problems. Rice is commonly grown by transplanting seedlings into puddled soils in Asia. This production system is labour, water and energy intensive and is becoming less profitable as these resources are becoming increasingly scarce. It also deteriorates the physical properties of soil, adversely affects the performance of succeeding upland crops and contributes to methane emissions. These factors demand a major shift from puddled transplanting to direct seeding of rice (DSR) in irrigated rice ecosystems. However, large scale adoption of DSR practices has been held back by poor crop establishment or a total loss of the crop 
stand due to improper levelled fields, heavy rainfall and poor drainage, which lead to the accumulation of water of varying depths immediately after sowing or during the early stages of seedling growth. The hazards of flooding right after sowing or during germination can discourage farmers from adopting DSR technology or force them to abandon this practice.

Consequently, developing high yielding varieties that can withstand flooding during germination and early growth is essential for sustainability of practicing direct seeding for rice crop establishment. Availability of suitable genetic donors will be a key to introduce tolerance to anaerobic germination into elite cultivars and popular genotypes.

Several studies revealed that rice has enormous exploitable variation in tolerance of flooding during germination. This high magnitude of variability provides an opportunity for selection to evolve a variety having desirable characters. Information on character association, direct and indirect effects contributed by each character towards yield will be an added advantage in aiding the selection process.

Yield is the end product of multiplicative interaction between various yield components and this necessitates a thorough understanding of character association and direct and indirect effects contributed by each character on grain yield before launching any breeding programme. Correlation and path analysis establish the extent of association between yield and its components and also bring out relative importance of their direct and indirect effects, thus giving an obvious understanding of their association with grain yield. Ultimately, this kind of analysis could help the breeder to design the selection strategies for improving grain yield. Hence, in the light of above scenario, the present investigation was carried out with the objective of determining the interrelationship between anaerobic germination traits, yield and its contributing characters as well as identifying the characters to be considered for selecting better genotypes suitable for the development of high yielding varieties with tolerance to the submergence during the germination.

\section{Materials and Methods}

The field experiment was conducted during kharif, 2016 at ICAR-Indian Institute of Rice Research Farm, ICRISAT campus, Patancheru, Hyderabad, India, situated at $17.53^{\circ} \mathrm{N}$ latitude, $78.27^{0} \mathrm{E}$ longitude and altitude of $545 \mathrm{~m}$ above mean sea level. Twenty five $F_{1}$ hybrids of rice along with their ten parents and three standard checks were sown separately in raised bed nursery. Thirty days old seedlings of each genotype were transplanted in 5 rows of $3 \mathrm{~m}$ length by adopting a spacing of $20 \mathrm{~cm}$ between rows and $15 \mathrm{~cm}$ between plants within a row in Randomized Block Design replicated thrice. All the necessary precautions were taken to maintain uniform plant population of each genotype per replication. All the recommended package of practices was adopted besides providing necessary prophylactic plant protection measures to raise a good crop.

Data were recorded on a total of twelve metric characters. Among them seven characters viz., plant height, total number of tillers per hill, number of productive tillers per hill, panicle length, total number of grains per panicle, spikelet fertility and single plant yield were recorded on five randomly selected plants in each plot. Days to $50 \%$ flowering was recorded on plot basis. 1000-grain weight was recorded per replication in each genotype. While three anaerobic germination traits were viz., anaerobic germination percentage $(\%)$, seedling length $(\mathrm{cm})$ and 
seedling vigour index I recorded as per the standard procedure given by ICAR-IIRR.. The data collected on all the characters were subjected to standard methods of analysis of variance (Panse and Sukhatme, 1985). The genotypic and phenotypic correlation coefficients were calculated using the method given by Falconer (1981) and path coefficient analysis were worked as suggested by Wright (1921) and Dewey and Lu (1959).

\section{Results and Discussion}

The analysis of variance revealed the existence of significant differences among the genotypes for all the traits, indicating the existence of sufficient variation in the material studied.

Hence, the data were further subjected to correlation (Table 1) and path coefficient analyses (Table 2) to estimate the association existing between anaerobic germination traits, yield and its contributing characters and the direct and indirect effects of these traits on yield, respectively.

High genotypic correlations, in general, as compared to their phenotypic counterparts indicated the existence of strong inherent association between the characters which might be due to the masking or modifying effect of the environment on the genetic association between the characters.

Single plant yield registered positive significant association with number of tiller per hill $(0.5661 * * / 0.5376 * *)$ and number of productive tillers per hill $\left(0.5478 * * / 0.5207^{* *}\right)$ which were in agreement with the findings of Patel et al., (2017) for number of tillers per hill and Devi et al., (2017) for number of productive tillers per hill. From the results, it was evident that increased number of tillers and productive tillers per plant which inturn helped to increase number of panicles, leading to increased single plant yield. Panicle length $(0.5292 * * / 0.4850 * *) \quad$ expressed positive significant association with single plant yield by accommodating more number of grains per panicle. Similar reports were recorded earlier by Umarani et al., (2014) and Devi et al., (2017). Spikelet fertility $(0.4485 * * / 0.4008 * *)$, number of grains per panicle $(0.3696 * * / 0.3402 * *)$ and 1000 -grain weight $\quad(0.1832 * * / 0.1841 * *) \quad$ exhibited positive significant association with single plant yield, which was quite expected, as increased expression of these traits ultimately had direct bearing on single plant yield.

These results are in agreement with the findings of Hasan et al., (2013) and Tiwari (2017) for spikelet fertility, Umarani et al., (2014) and Patel et al., (2017) for number of grains per panicle and Tiwari (2017) for 1000-grain weight indicating that these characters were important for yield improvement.

Positive but non-significant association of single plant yield was observed with plant height $(0.1458 / 0.1411)$, days to $50 \%$ flowering $(0.0858 / 0.0881)$ and anaerobic germination percentage (0.0545/0.0519). Patel et al., (2017) reported similar results for plant height and days to $50 \%$ flowering. Negative but non-significant correlation was reported with seedling length (-0.0882/$0.0840)$ and seedling vigour index I (-0.0354/$0.0337)$.

According to NeWall and Eberhart (1961) when two characters show negative phenotypic and genotypic correlation it would be difficult to exercise simultaneous selection for these characters in the development of a variety. Hence, under such situations, judicious selection programme might be formulated for simultaneous improvement of such important developmental and component characters. 
Table.1 Estimates of genotypic and phenotypic correlation coefficients for anaerobic germination traits, yield and its contributing traits in rice

\begin{tabular}{|c|c|c|c|c|c|c|c|c|c|c|c|c|c|}
\hline Trait & & $\begin{array}{c}\text { AGP } \\
(\%)\end{array}$ & SL (cm) & SVI I & DFF & P H (cm) & NTPH & NPTPH & PL (cm) & NGPP & SF (\%) & $\begin{array}{c}\text { 1000- } \\
\text { GW (g) }\end{array}$ & SPY (g) \\
\hline \multirow{2}{*}{$\begin{array}{c}\text { AGP } \\
(\%)\end{array}$} & G & 1.0000 & $0.6839 * *$ & $0.8517 * *$ & $0.2589 * *$ & $0.6349 * *$ & 0.0811 & $0.2477 * *$ & 0.1698 & $-0.4320 * *$ & -0.1624 & $0.3014 * *$ & 0.0545 \\
\hline & $\mathbf{P}$ & 1.0000 & $0.6796 * *$ & $0.8485^{* *}$ & $0.2519 * *$ & $0.6324 * *$ & 0.0799 & $0.2423 * *$ & 0.1569 & $-0.4094 * *$ & -0.1410 & $0.2841 * *$ & 0.0519 \\
\hline \multirow[t]{2}{*}{ SL (cm) } & G & & 1.0000 & $0.9373 * *$ & -0.0601 & $0.2837 * *$ & $0.2704 * *$ & $0.3946^{* *}$ & $-0.2007 *$ & -0.1167 & $-0.5555^{* *}$ & $0.2504 * *$ & -0.0882 \\
\hline & $\mathbf{P}$ & & 1.0000 & $0.9366 * *$ & -0.0567 & $0.2801 * *$ & $0.2575 * *$ & $0.3762 * *$ & $-0.1920 *$ & -0.1081 & $-0.4742 * *$ & $0.2408 * *$ & -0.0840 \\
\hline \multirow[t]{2}{*}{ SVI I } & $\mathbf{G}$ & & & 1.0000 & 0.0357 & $0.4620 * *$ & $0.2080^{*}$ & $0.3392 * *$ & -0.0055 & $-0.2632 * *$ & $-0.4161 * *$ & $0.3124 * *$ & -0.0354 \\
\hline & $\mathbf{P}$ & & & 1.0000 & 0.0346 & $0.4572 * *$ & $0.1987^{*}$ & $0.3266^{* *}$ & -0.0116 & $-0.2458 * *$ & $-0.3595 * *$ & $0.2990 * *$ & -0.0337 \\
\hline \multirow[t]{2}{*}{ DFF } & G & & & & 1.0000 & $0.4775^{* *}$ & -0.0307 & 0.0626 & $0.2484 * *$ & -0.0759 & -0.1361 & $-0.5418 * *$ & 0.0858 \\
\hline & $\mathbf{P}$ & & & & 1.0000 & $0.4655^{* *}$ & -0.0222 & 0.0640 & $0.2388^{*}$ & -0.0826 & -0.1182 & $-0.5099 * *$ & 0.0881 \\
\hline \multirow[t]{2}{*}{ PH (cm) } & G & & & & & 1.0000 & -0.1573 & -0.0651 & $0.5486 * *$ & $-0.5725^{* *}$ & -0.1198 & -0.0418 & 0.1458 \\
\hline & $\mathbf{P}$ & & & & & 1.0000 & -0.1555 & -0.0640 & $0.5155^{* *}$ & $-0.5375^{* *}$ & -0.1118 & -0.0361 & 0.1411 \\
\hline \multirow[t]{2}{*}{ NTPH } & G & & & & & & 1.0000 & $0.8914 * *$ & 0.0361 & $0.2565^{* *}$ & 0.0293 & 0.1740 & $0.5661 * *$ \\
\hline & $\mathbf{P}$ & & & & & & 1.0000 & $0.8784 * *$ & 0.0169 & $0.2131 *$ & 0.0402 & 0.1762 & $0.5376^{* *}$ \\
\hline \multirow[t]{2}{*}{ NPTPH } & $\mathbf{G}$ & & & & & & & 1.0000 & -0.0094 & $0.2109 *$ & 0.0157 & $0.2267^{*}$ & $0.5478 * *$ \\
\hline & $\mathbf{P}$ & & & & & & & 1.0000 & -0.0172 & 0.1839 & 0.0210 & $0.2244^{*}$ & $0.5207 * *$ \\
\hline \multirow[t]{2}{*}{ PL (cm) } & G & & & & & & & & 1.0000 & -0.1737 & 0.2145 & -0.0638 & $0.5292 * *$ \\
\hline & $\mathbf{P}$ & & & & & & & & 1.0000 & -0.1422 & 0.1613 & -0.0700 & $0.4850 * *$ \\
\hline \multirow[t]{2}{*}{ NGPP } & $\mathbf{G}$ & & & & & & & & & 1.0000 & 0.0860 & -0.0766 & $0.3696 * *$ \\
\hline & $\mathbf{P}$ & & & & & & & & & 1.0000 & 0.0045 & -0.0771 & $0.3402 * *$ \\
\hline \multirow[t]{2}{*}{ SF (\%) } & $\mathbf{G}$ & & & & & & & & & & 1.0000 & $0.4228 * *$ & $0.4485 * *$ \\
\hline & $\mathbf{P}$ & & & & & & & & & & 1.0000 & $0.3364 * *$ & $0.4008 * *$ \\
\hline \multirow{2}{*}{$\begin{array}{c}\text { 1000- } \\
\text { GW (g) }\end{array}$} & G & & & & & & & & & & & 1.0000 & $0.1832 *$ \\
\hline & $\mathbf{P}$ & & & & & & & & & & & 1.0000 & 0.1841 ** \\
\hline
\end{tabular}

*Significant at 5 per cent level; **Significant at 1 per cent level

G - Genotypic level; P - Phenotypic level

*AGP (\%) - Anaerobic germination percentage (\%); SL (cm) - Seedling length (cm); SVI I - Seedling vigour index I; DFF - Days to 50 \% flowering; PH (cm) - Plant height; NTPP - Number of tillers per plant; NPTP - Number of productive tillers per plant; PL (cm) - Panicle length (cm); NGPP - Number of grains per panicle; SF (\%) - Spikelet

fertility (\%); 1000-GW (g) - 1000-grain weight (g); SPY (g) - Single plant yield (g) 
Table.2 Estimates of direct and indirect effects of anaerobic germination traits, yield contributing traits on single plant yield in rice

\begin{tabular}{|c|c|c|c|c|c|c|c|c|c|c|c|c|c|}
\hline Trait & & AGP $(\%)$ & SL (cm) & SVI I & DFF & P H (cm) & NTPH & NPTPH & PL (cm) & NGPP & SF (\%) & $\begin{array}{c}\text { 1000- } \\
\text { GW (g) }\end{array}$ & SPY (g) \\
\hline \multirow[t]{2}{*}{$\operatorname{AGP}(\%)$} & $\mathbf{G}$ & 0.2960 & 0.2025 & 0.2521 & 0.0767 & 0.1880 & 0.0240 & 0.0733 & 0.0503 & -0.1279 & -0.0481 & 0.0892 & 0.0545 \\
\hline & $\mathbf{P}$ & 0.1955 & 0.1329 & 0.1659 & 0.0492 & 0.1236 & 0.0156 & 0.0474 & 0.0307 & -0.0800 & -0.0276 & 0.0555 & 0.0519 \\
\hline \multirow[t]{2}{*}{ SL (cm) } & G & 0.1945 & 0.2844 & 0.2665 & -0.0171 & 0.0807 & 0.0769 & 0.1122 & -0.0571 & -0.0332 & -0.1580 & 0.0712 & -0.0882 \\
\hline & $\mathbf{P}$ & 0.1448 & 0.2131 & 0.1996 & -0.0121 & 0.0597 & 0.0549 & 0.0802 & -0.0409 & -0.0230 & -0.1011 & 0.0513 & -0.0840 \\
\hline \multirow[t]{2}{*}{ SVI I } & G & -0.5404 & -0.5947 & -0.6345 & -0.0226 & -0.2932 & -0.1319 & -0.2152 & 0.0035 & 0.1670 & 0.2640 & -0.1982 & -0.0354 \\
\hline & $\mathbf{P}$ & -0.4433 & -0.4894 & -0.5225 & -0.0181 & -0.2389 & -0.1038 & -0.1707 & 0.0061 & 0.1285 & 0.1879 & -0.1562 & -0.0337 \\
\hline \multirow[t]{2}{*}{ DFF } & G & -0.0624 & 0.0145 & -0.0086 & -0.2410 & -0.1151 & 0.0074 & -0.0151 & -0.0599 & 0.0183 & 0.0328 & 0.1306 & 0.0858 \\
\hline & $\mathbf{P}$ & -0.0336 & 0.0076 & -0.0046 & -0.1333 & -0.0620 & 0.0030 & -0.0085 & -0.0318 & 0.0110 & 0.0158 & 0.0680 & 0.0881 \\
\hline \multirow[t]{2}{*}{ PH (cm) } & G & 0.3202 & 0.1431 & 0.2330 & 0.2408 & 0.5043 & -0.0793 & -0.0328 & 0.2766 & -0.2887 & -0.0604 & -0.0211 & 0.1458 \\
\hline & $\mathbf{P}$ & 0.2908 & 0.1288 & 0.2102 & 0.2140 & 0.4598 & -0.0715 & -0.0294 & 0.2370 & -0.2472 & -0.0514 & -0.0166 & 0.1411 \\
\hline \multirow[t]{2}{*}{ NTPH } & G & 0.0213 & 0.0709 & 0.0545 & -0.0081 & -0.0412 & 0.2620 & 0.2336 & 0.0095 & 0.0672 & 0.0077 & 0.0456 & $0.5661 * *$ \\
\hline & $\mathbf{P}$ & 0.0245 & 0.0791 & 0.0610 & -0.0068 & -0.0478 & 0.3072 & 0.2698 & 0.0052 & 0.0655 & 0.0124 & 0.0541 & $0.5376^{* *}$ \\
\hline \multirow[t]{2}{*}{ NPTPH } & G & 0.0733 & 0.1168 & 0.1004 & 0.0185 & -0.0193 & 0.2638 & 0.2959 & -0.0028 & 0.0624 & 0.0047 & 0.0671 & $0.5478^{* *}$ \\
\hline & $\mathbf{P}$ & 0.0566 & 0.0878 & 0.0763 & 0.0149 & -0.0149 & 0.2051 & 0.2335 & -0.0040 & 0.0429 & 0.0049 & 0.0524 & $0.5207^{* *}$ \\
\hline \multirow[t]{2}{*}{ PL (cm) } & G & 0.0554 & -0.0655 & -0.0018 & 0.0811 & 0.1791 & 0.0118 & -0.0031 & 0.3266 & -0.0567 & 0.0701 & -0.0208 & $0.5292 * *$ \\
\hline & $\mathbf{P}$ & 0.0481 & -0.0589 & -0.0036 & 0.0733 & 0.1581 & 0.0052 & -0.0053 & 0.3068 & -0.0436 & 0.0495 & -0.0215 & $0.4850 * *$ \\
\hline \multirow[t]{2}{*}{ NGPP } & G & -0.2279 & -0.0616 & -0.1389 & -0.0400 & -0.3021 & 0.1353 & 0.1113 & -0.0916 & 0.5276 & 0.0454 & -0.0404 & $0.3696^{* *}$ \\
\hline & $\mathbf{P}$ & -0.1996 & -0.0527 & -0.1199 & -0.0403 & -0.2621 & 0.1039 & 0.0896 & -0.0694 & 0.4876 & 0.0022 & -0.0376 & $0.3402 * *$ \\
\hline \multirow[t]{2}{*}{ SF (\%) } & G & -0.0524 & -0.1792 & -0.1343 & -0.0439 & -0.0387 & 0.0094 & 0.0051 & 0.0692 & 0.0277 & 0.3226 & 0.1364 & $0.4485^{* *}$ \\
\hline & $\mathbf{P}$ & -0.0418 & -0.1406 & -0.1066 & -0.0351 & -0.0332 & 0.0119 & 0.0062 & 0.0478 & 0.0013 & 0.2966 & 0.0998 & $0.4008 * *$ \\
\hline \multirow[t]{2}{*}{ 1000-GW (g) } & G & -0.0230 & -0.0191 & -0.0239 & 0.0414 & 0.0032 & -0.0133 & -0.0173 & 0.0049 & 0.0058 & -0.0323 & -0.0764 & $0.1832 *$ \\
\hline & $\mathbf{P}$ & 0.0099 & 0.0084 & 0.0104 & -0.0178 & -0.0013 & 0.0062 & 0.0078 & -0.0024 & -0.0027 & 0.0117 & 0.0349 & $0.1841^{* *}$ \\
\hline $\begin{array}{l}\text { G - Genotypic leve } \\
\text { Bold values - direc } \\
\text { *AGP }(\%) \text { - Anae }\end{array}$ & ; P- & $\begin{array}{l}\text { Phenotypic le } \\
\text { cts; Normal v }\end{array}$ & $\begin{array}{l}\text { el } \\
\text { lues - indire }\end{array}$ & effects & & & & & 18 & $\sigma_{i}$ & $\mathrm{P}$ & $\begin{array}{l}=0.46 \\
\text { level }\end{array}$ & - \\
\hline
\end{tabular}


Grain yield, which is the major economic character in rice depends on several component traits, which are mutually related. Mere change in any one of the component trait would ultimately disturb the complex. Hence, these related traits have to be analyzed for their direct effects as well as the indirect effects through other component characters on grain yield. Therefore, the total correlations were partitioned into direct and indirect effects.

Path coefficient analysis revealed that number of grains per panicle $(0.5276 / 0.4876)$ exserted the highest positive direct effect on grain yield followed by plant height (0.5043/0.4598), panicle length $(0.3266 / 0.3068), \quad$ spikelet fertility (0.3226/0.2966), anaerobic germination percentage $(0.2960 / 0.1955)$, number of productive tillers per hill (0.2959/0.2335), seedling length $(0.2844 / 0.2131)$ and number of tillers per hill $(0.2620 / 0.3072)$ indicating that the selection for these characters was likely to bring about an overall improvement in single plant yield directly. Therefore, it is suggested that preference should be given to these characters in the selection programme to isolate superior lines with genetic potentiality for high yield in rice genotypes.

These results are in agreement with the findings of Nagaraju et al., (2013) and Umarani et al., (2014) for total number of grains per panicle, Kishore et al., (2015) and Lakshmi et al., (2017) for plant height, Lingaiah et al., (2014) and Moosavi et al., (2015) for panicle length, Hasan et al., (2013) and Umarani et al., (2014) for spikelet fertility and Gangashetty et al., (2013) and Kalyan et al., (2017) for number of productive tillers per hill and number of tillers per hill. Negative direct effects on grain yield were exhibited by seedling vigour index I ($0.6345 / 0.5225)$ and days to $50 \%$ flowering ($0.2410 /-0.333)$ in decreasing order, respectively. While, 1000-grain weight recorded both negative (-0.0764) and positive direct (0.0349) effects on grain yield at phenotypic and genotypic levels, respectively. These results were in confirmity with the findings of Rao et al., (2014) and Devi et al., (2017) days to $50 \%$ flowering.

In conclusion, critical analysis of results obtained from character association and path analysis indicated that the traits viz., number of number of grains per panicle, panicle length, spikelet fertility, number of productive tillers per hill and number of tillers per hill displayed significant positive correlation as well as positive direct effect on single plant yield. The positive direct effects of these traits on yield might have resulted in strong genetic correlations. Plant height, anaerobic germination percentage and seedling length exserted the positive direct effect on grain yield, but it had positive-non significant association with yield which might be due to the negative indirect effects manifested through other component traits. Hence, due emphasis should be given to these traits in formulating selection criteria to bring yield as well as tolerance to the submergence during germination.

\section{Acknowledgements}

I humbly thank the Chairman and members of my advisory committee for their technical guidance and support and authorities of "PJTSAU, Rajendranagar, Hyderabad" and "DST-INSPIRE Programme", Government of India for the financial help rendered in the form of fellowship during during my study period.

\section{References}

Devi, K.R., Satish, B., Chandra, N., Lingaiah, Y., Hari and Venkanna, V. 2017. Analysis of variability, correlation and 
path coefficient studies for yield and quality traits in rice (Oryza sativa L.). Agricultural Science Digest. 37 (1): 1-9.

Dewey, O.R. and Lu, K.H. 1959. Correlation and path coefficient analysis of components of crested wheat grass seed production. Journal of Agronomy. 51: 515-518.

Falconer, D.S. 1981. Introduction to Quantitative Genetics. Oliver and Boyd, London. 340.

Gangashetty, P.I., Salimath, P.M and Hanamaratti, N.G. 2013. Genetic variability studies in genetically diverse non-basmati local aromatic genotypes of rice (Oryza sativa L.). Rice Genomics and Genetics. 4 (2): 4-8.

Hasan, M.U., Kulsum, M.J., Akter, A., Masuduzzaman, A.S.M and Ramesha, M.S. 2013. Genetic variability and character association for agronomic traits in hybrid rice (Oryza sativa L.). Bangladesh Journal of Plant Breeding and Genetics. 24 (1): 45-51.

Kalyan, B., Krishna, K.V.R and Rao, L.V.S. 2017. Path coefficient analysis for yield and yield contributing traits in rice (Oryza sativa L.) genotypes. International Journal of Current Microbiology and Applied Sciences. 6 (7): 2680-2687.

Kishore, N.S., Srinivas, T., Nagabhushanam, U., Pallavi, M and Sameera, S.K. 2015. Genetic variability, correlation and path analysis for yield and yield components in promising rice (Oryza sativa L.) genotypes. SAARC Journal of Agriculture. 13 (1): 99-108.

Lakshmi, Rao, M.V.B., Raju, Ch.S and Reddy, S.N. 2017. Variability, correlation and path analysis in advanced generation of aromatic rice (Oryza sativa L.). International Journal of Current Microbiology and Applied Sciences. 6 (7): 1798-1806.
Lingaiah, N., Venkanna, V., Cheralu, C and Chandra, B.S. 2014. Correlation and path analysis for yield and yield attributes in mid early group genotypes of rice (Oryza sativa L.). International Journal of Innovative Science, Engineering \& Technology. 1 (9): 79 82.

Moosavi, M., Ranjbar, G., Zarrini, H.N and Gilani, A. 2015. Correlation between morphological and physiological traits and path analysis of grain yield in rice genotypes under Khuzestan conditions. An International Journal. 7 (1): 43- 47.

Nagaraju, C., Sekhar, M.R., Reddy, K.H and Sudhakar, P. 2013. Correlation between traits and path coefficient analysis for grain yield and other components in rice (Oryza sativa L.) genotypes. International Journal of Biology and Pharmaceutical Technology. 4 (3): 137142.

NeWall, L.C and Eberhart, S.A. 1961. Clone and progeny evaluation in the improvement of switch grass (Panicum virgatum L.). Crop Science. 1: 117-121.

Panse, V.G and Sukhatme, P.V. 1985. Statistical Methods for Agricultural Workers. ICAR, New Delhi. 235 - 246.

Patel, J.R., Dixita, K., Patel, K.N., Prajapati, N.V., Soni and Patel, A. 2017. Correlation and path coefficient analysis in rainfed upland rice (Oryza sativa L.). Environment and Ecology. 35 (2): 789794.

Rao, V.T., Mohan, Y.C., Bhadru, D., Bharathi, D and Venkanna, V. 2014. Genetic variability and association analysis in rice. International Journal of Applied Biology and Pharmaceutical Technology. 5(2): 63-65.

Tiwari, J.K. 2017. Association analysis and selection strategies for various yield contributing traits in rice genotypes. Applied Biological Research. 19 (1): 35-40. 
Umarani, E., Radhika, K., Subbarao, L.V. and Padma, V. 2014. Studies on interrelationships, cause and effects for yield, its contributing traits and grain quality parameters in landraces of rice (Oryza sativa L.). Progressive
Research-an International Journal. 3: 609-613.

Wright, S. 1921. Correlation and causation. Journal of Agricultural Research. 20: 557-585.

\section{How to cite this article:}

Umarani, E., V. Hemalatha, L.V. Subbarao, C.N. Neeraja, Suneetha Kota and Narender Reddy, S. 2019. Studies on Character Association and Path Coefficient Analysis for Anaerobic Germination Traits, Yield and its Contributing Characters in Rice (Oryza sativa L.). Int.J.Curr.Microbiol.App.Sci. 8(04): 355-362. doi: https://doi.org/10.20546/ijcmas.2019.804.039 